\title{
Influence of Mechanical Scratches on Recorded Magnetization Stability of Perpendicular Recording Media
}

\author{
Katsumasa Nagano, Syota Sasaki, and Masaaki Futamoto \\ Faculty of Science and Engineering, Chuo University, 1-13-27 Kasuga, Bunkyou-ku, Tokyo 112-8551, Japan
}

\begin{abstract}
The stability of recorded magnetization on hard disk drives (HDDs) is influenced by external environments, such as temperature and magnetic fields. Small scratches are frequently formed on an HDD medium surface on contact with the magnetic head. The influence of a perpendicular magnetic field and mechanical scratching on the magnetization structural stability of perpendicular recording media was investigated by using a magnetic force microscope. The magnetization structure started to change at lower magnetic fields in an area near and below mechanical scratches when compared with normal areas with no scratches. A quantitative analysis of variations in the magnetization structure was carried out by taking into consideration the difference in MFM images observed for the same sample area before and after exposing the sample to different magnetic fields.
\end{abstract}

Keywords: perpendicular recording media, mechanical scratches, magnetization stability, magnetic force microscope

\section{垂直磁気記録媒体の記録磁化安定性に及ぼすスクラッチの影響}

長野克政・佐々木翔太・二本正昭

中大理工，東京都文京区春日 1-13-27（テ112-8551）

\section{1. はじめに}

2005 年に垂直記録方式がハードディスクドライブ (HDD) に 導入されて以来，記録密度は年率 40～50\%で増大し続けている. 記録密度の増大に伴ってビット内に含まれる磁性結晶粒の数や寸 法が減少し，磁性結晶粒の磁気エネルギーが低下寸るため，温度 や外部磁場などの外部環境に対寸る記録ビットの安定性が問題と なる．記録磁化状態の安定性は，これまでにコンピュータシミュ レーション 1,2$)$ ，スピンスタンドを用いた記録信号強度の時間変化 測定 ${ }^{3,4)}$ ，磁気力顕微鏡 (MFM) を用いた磁化状態観察 5-7)などの 方法で検討されている.

一方, HDD の高密度化に対応してヘッドとディスク間の距離を 近づける必要があり，スペーシングは既に $10 \mathrm{~nm}$ 以下となってい る. 狭スペーシング条件下では, HDD の動作中にヘッドがディス クに接触し，接触によってディスク表面にスクラッチが形成され る可能性が増大寸る. スクラッチが形成された場合, HDD の記録 磁化状態に及ぼす影響などが調べ始められている ${ }^{8,9)}$. 面内磁気記 録方式による HDD ディスク表面に記録磁性層まで達するスクラ ッチが形成されるとそのスクラッチ領域の記録ビットが物理的な ダメージを受けて記録磁気情報が消失することが報告されている 9).また，スクラッチ深さが記録磁性膜に達しない浅い場合でも, コンタクト時の応力の影響により垂直磁気記録媒体のキャップ磁 性層とグラニュラー磁性層が塑性変形寸ることによって c 軸が傾 斜し，外部からの磁場により減磁が起こり易くなることが報告さ れている 10). しかしながら，垂直磁気記録方式による HDD ディ スクについて記録磁性層に達するスクラッチが存在した場合，温 度や磁場などの外部環境が記録ビットの安定性に及ぼす影響を調 ベた研究報告例は殆どない，我々は最近，記録磁性層にまで達す るスクラッチが形成された垂直媒体の記録磁化状態の安定性に及 ぼす温度の効果を調べ，スクラッチの直下および周囲部領域はス クラッチの無い領域に比べて低い温度で磁化状態の変化が生じ始
めることを明らかにしている ${ }^{11)}$. 本研究では, HDD ディスク表面 上に記録磁性層に達寸るスクラッチを形成し，スクラッチの深さ を変えた場合，スクラッチの直下および周辺部の記録磁化状態に 及ぼす外部磁場の影響を詳細に調べることを目的とした。垂直磁 気記録媒体に垂直方向で磁場印加処理を行った場合の磁化状態変 化を MFM により観察した. スクラッチを形成した磁気ディスク 試料において，スクラッチ下部では深さが記録磁性層に達してい る領域と達していない領域を区別し，さらにスクラッチ周辺部に ついて記録磁化状態の安定性に及ぼす外部磁場の影響について検 討を行った.

\section{2. 実験方法}

\section{1 観察試料および実験装置}

観察試料には, 市販の垂直記録方式のHDDディスクを用いた。 HDD をPC に装着してランダムデータを記録した後, ディスクを 小片に切断し，これを観察試料として用いた. この HDD ディス クの最大面記録密度は $163 \mathrm{~Gb} / \mathrm{in}^{2}$ である. カ一効果を用いて室温 で測定した磁化曲線を Fig. 1 に示寸。保磁力は 4.7 kOeである. HDD ディスクの膜面垂直方向の膜厚測定を X 線による反射率測

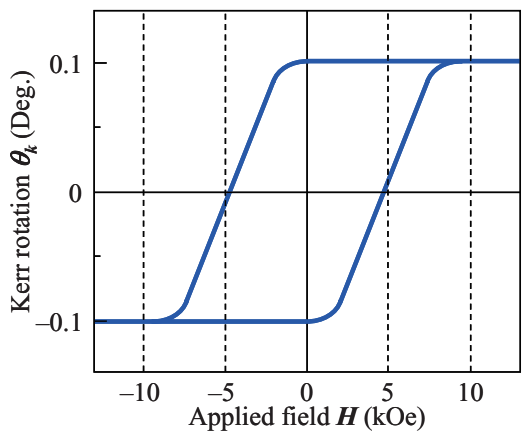

Fig. 1 Kerr hysteresis loop of sample. 

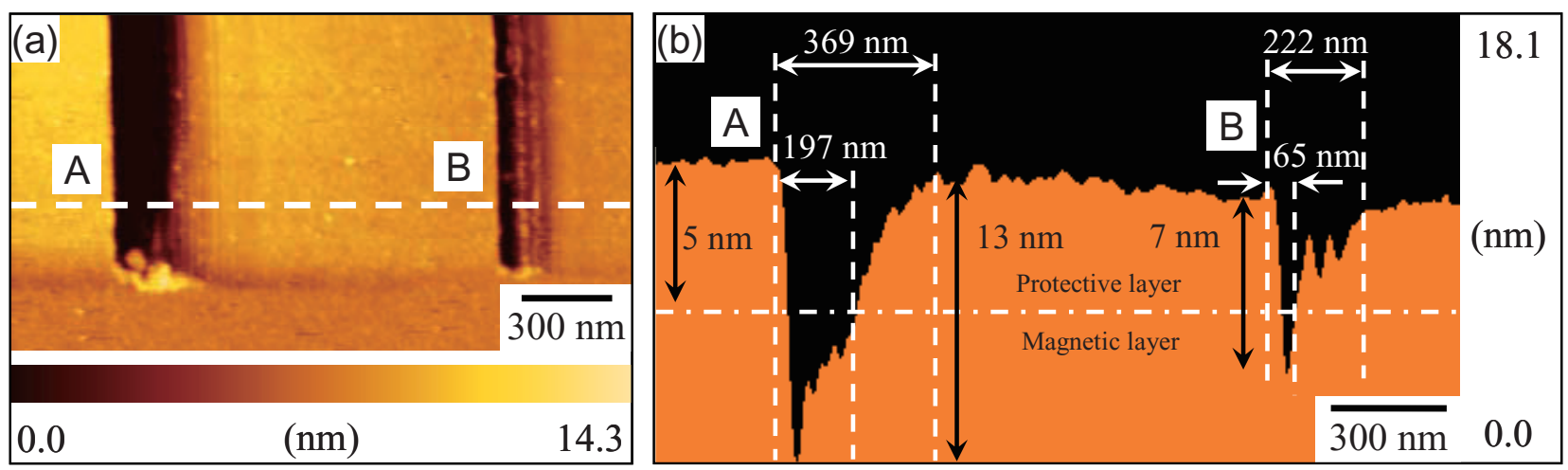

Fig. 2 (a) AFM image of perpendicular recording medium with two mechanical scratches. (b) Cross-sectional profile of medium surface measured along dotted line in (a).
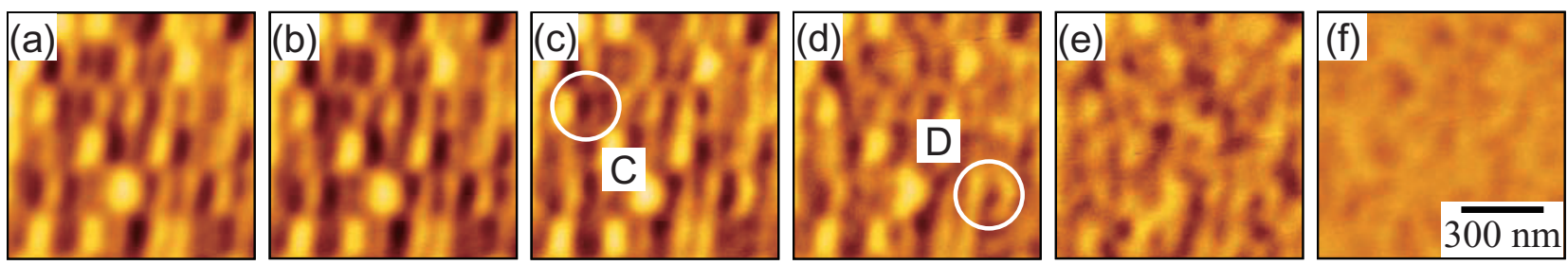

Fig. 3 MFM images of area with no mechanical scratches. Variations in MFM image after perpendicular magnetic fields of (a) 0, (b) 2, (c) 3, (d) 4, (e) 5, and (f) $6 \mathrm{kOe}$ were applied.

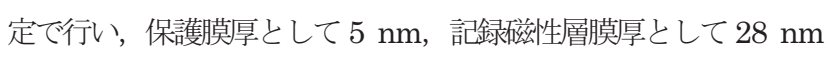
の值を得た.

ディスク試料へのスクラッチ形成にはダイヤモンド被覆した Si 製探針を用いた，原子間力顕微鏡 (AFM) を用いて，ダイヤモン ド被覆探針のカンチレバーのたわみ量を適切に制御することによ って, 深さの異なるスクラッチをディスク試料表面に形成した. スクラッチの幅や深さの計測には AFM を用いた。測定時に使用 した $\mathrm{AFM}$ 探針の曲率半径は $20 \mathrm{~nm}$ である. ディスク試料の外部 磁場処理は, 室温で電磁石を用いて行った. 磁場印加強度を $1 \mathrm{kOe}$ ごとに $6 \mathrm{kOe}$ までステップ状に増大しながら膜面垂直方向へ印加 した. 磁場印加の時間は 30 秒とした. 磁場印加を行う毎に, ディ スク試料の AFM および MFM 観察を SII ナノテクノロジー社製 の環境制御型走査プローブ顕微鏡（SPA300HV/SPI4000）を用い て行った. MFM 探針には，同社製のSI-MF40を用いた。探針一 の被覆磁性体材料, 膜厚, 保磁力, 曲率半径はそれぞれ $\mathrm{CoCrPt}$, $50 \mathrm{~nm}, 200 \mathrm{Oe}, 35 \mathrm{~nm}$ である.

本実験では，ディスク試料のプローブ顕微鏡への装脱着を繰り 返し行って, しかも同一箇所の MFM 像観察を行った. この際, 試料位置合わせでは既開発技術7を採用し, さらに繰り返し観察に 伴う MFM 画像のドリフトは AFM 像を参照して補正した. 補正 による画像变形誤差は 1 ピクセル以内に抑えることができた ${ }^{12)}$.

\section{2 スクラッチの形成および評価}

スクラッチの形成は，ダイヤモンド被覆探針を AFM に取り付 けてディスク試料と探針を接触させた状態で直線方向に走査寸る ことによって行った. 探針先端にかかる荷重調整は, ダイヤモン
ド被覆探針のカンチレバーのたわみ量を適切に制御することによ って行った. 探針先端こかかる荷重は，6１0 $\mu \mathrm{N}$ の範囲でほぼ一 定值に保って, $2.5 \mu \mathrm{m} / \mathrm{sec}$ の走査速度で直線方向に探針を 30 秒間 往復させてスクラッチを形成した. Fig. 2(a)に, この様な方法でデ イスク試料表面に形成した 2 つのスクラッチの AFM 像を示す. Fig. 2(b)は, Fig. 2(a)の AFM 像に示す点線上で測定した断面プロ ファイル像である. 断面プロファイル像より, スクラッチの最大 深さはA の場合 $13 \mathrm{~nm}, \mathrm{~B}$ の場合 $7 \mathrm{~nm}$ であり, 幅はA の場合 369 $\mathrm{nm}, \mathrm{B}$ の場合 $222 \mathrm{~nm}$ であることが分かる. A の場合は, X 線 測定で決定した保護膜厚 $(5 \mathrm{~nm})$ を考慮すると, ディスク保護膜 を超えて記録磁性膜中に $8 \mathrm{~nm}$ 程度の深さまで達していることに なる. また, 記録磁性層にまで達している領域はスクラッチの幅 $369 \mathrm{~nm}$ のうち $197 \mathrm{~nm}$ である. 一方, 深さが最大 $7 \mathrm{~nm}$ と浅い $\mathrm{B}$ の場合は, 記録磁性膜中への損傷は $2 \mathrm{~nm}$ 程度の深さに止まってお り, A と比べると磁生層に及ぼす影響は比較的小さいと考えられ る. B の場合, 記録磁生層にまで達している領域はスクラッチ幅 $222 \mathrm{~nm}$ のち $65 \mathrm{~nm}$ である. また, これら A, B のスクラッチ と記録トラックの成す角度は 80 度であり, スクラッチはほぼクロ ストラック方向と平行に形成されている.

\section{3. 実験結果}

\section{1 記録磁化状態に及ぼす外部磁場の影響}

Fig. 3 に, 初期状態およびディスク面に対して垂直に外部磁場を $2 \mathrm{kOe}$ から $6 \mathrm{kOe}$ まで $1 \mathrm{kOe}$ ごとにステップ状に増大しながら印 加処理した後に観察した同一領域の一連の MFM 像を示す. Fig. 

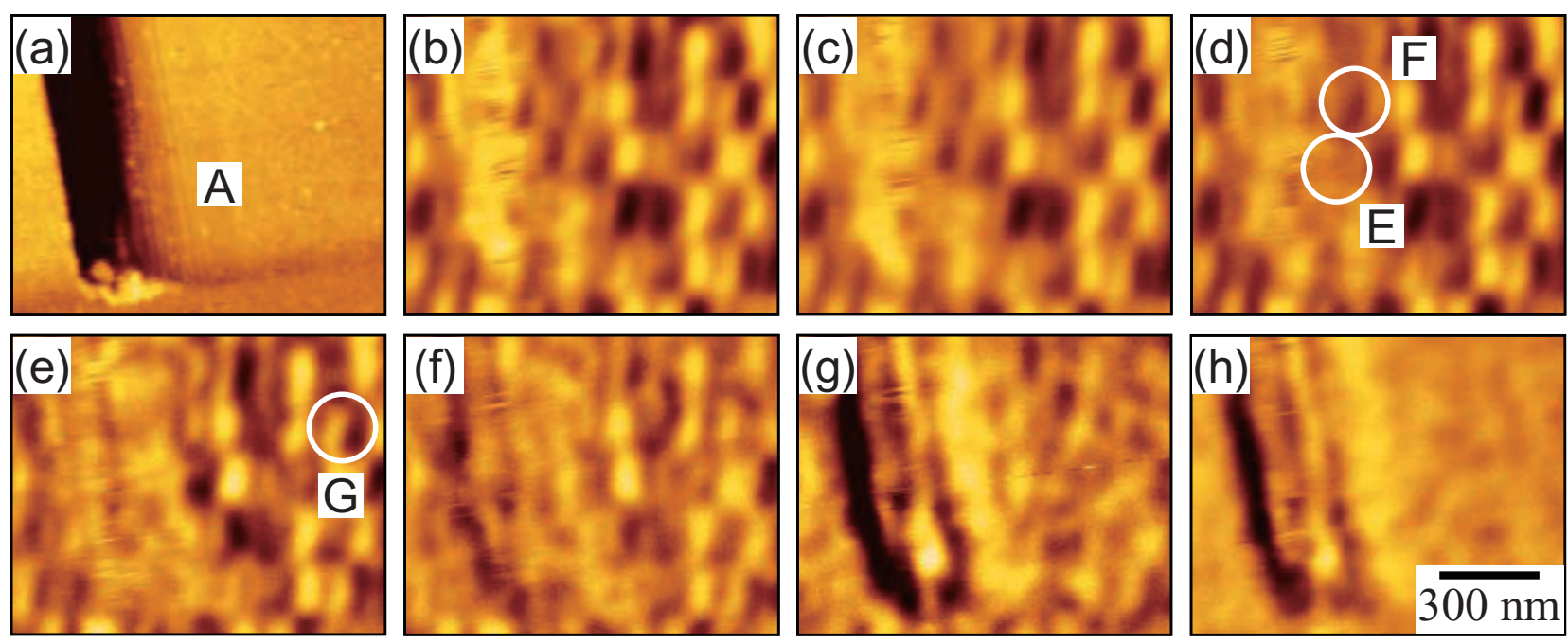

Fig. 4 AFM and MFM images of sample with a mechanical scratch. (a) AFM image of sample in Fig. 1 for area of A. (b)-(h) MFM images of the areas corresponding to AFM images observed after perpendicular magnetic fields of (b) 0 , (c) 1, (d) 2, (e) 3, (f) 4, (g) 5, and (h) 6 kOe were applied.
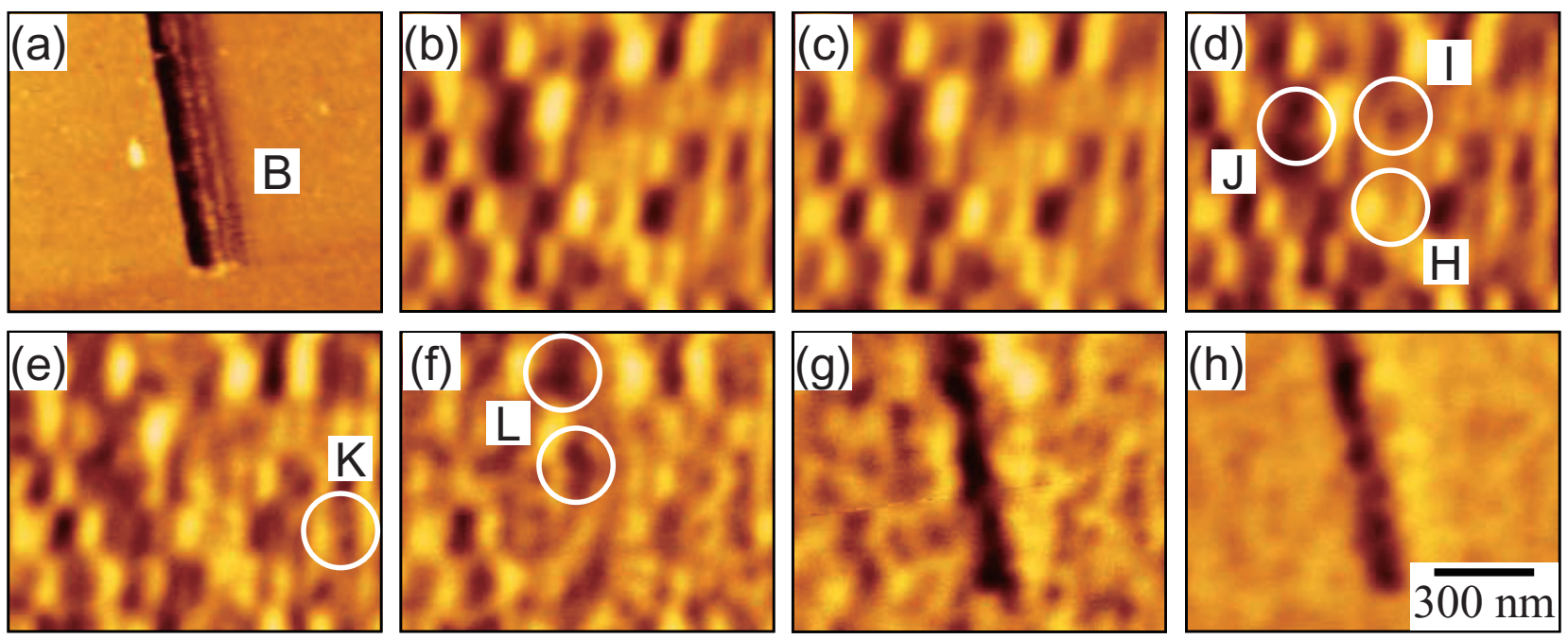

Fig. 5 AFM and MFM images of sample with a mechanical scratch. (a) AFM image of sample in Fig. 1 for area of B. (b)-(h) MFM images of area corresponding to AFM images observed after perpendicular magnetic fields of (b) 0 , (c) 1 , (d) 2 , (e) 3, (f) 4, (g) 5, and (h) 6 kOe were applied.

3(a)は，初期状態（磁場印加処理前）のMFM 像である. MFM 像 の水平方向が記録トラック方向に対応している. 隣接記録トラッ クがほぼ接触して観察されており，トラック間のガードバンドは 認められない，印加磁場強度 $2 \mathrm{kOe}$ では，初期状態と比べて記録 ビットの磁化状態に変化は殆ど認められない，しかし，3 kOe の 磁場印加処理により，(c)中の C 部をはじめ暗コントラストビット の端部に僅かながら磁化反転に対応する明コントラスト領域が認 められ始めている. $3 \mathrm{kOe}$ はこのディスク試料の保磁力 ( $4.7 \mathrm{kOe})$ に比べて $36 \%$ 低い 磁場である. $4 \mathrm{kOe}$ の磁場印加処理後の MFM 像(d)では，磁化反転が更に進行し，D 部に示寸ように，暗コント ラスト内部に明コントラスト領域が周囲から拡大侵入しているの が認められる. 保磁力以上の $5 \mathrm{kOe}$ の磁場を印加後には, 明コン トラスト領域の面積が更に拡大しており，記録磁化状態が全体的 に変化していることが分かる. 更に $6 \mathrm{kOe}$ の磁場印加処理後では,
明コントラスト領域の面積が更に拡大し，初期状態の磁化情報は 殆ど失われている.

\section{2 深いスクラッチの影響（最大深さ $13 \mathrm{~nm}$, 幅 $369 \mathrm{~nm}$ ）}

Fig. 4 に, スクラッチを形成したディスク試料の磁化状態の観察 結果を示す. Fig. 4(a)はAFM 像, Fig. 4(b) (h)はMFM 像で，(b) は磁場無印加状態，(c)〜(h)は1～6 kOe の外部磁場をそれぞれス テップ状に印加後に観察した同一箇所の MFM 像である. Fig. 4(a) に形態像で示した領域は, Fig. 2(b)の断面プロファイルとして 示したスクラッチ $\mathrm{A}$ に対応しており, スクラッチの最大深さは 13 nm である. Fig. 4(b)の磁場無印加状態では, スクラッチが保 護膜厚を超えて記録磁性層にまで及んでいる領域（スクラッチ左 端から $197 \mathrm{~nm}$ までの範囲) では磁化状態が既に変形し, 本来の 記録情報が失われていることが分かる. この領域は, 磁場印加強 
(a)

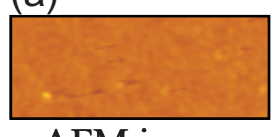

AFM image

(b)

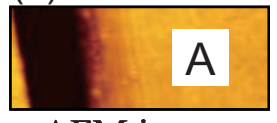

AFM image

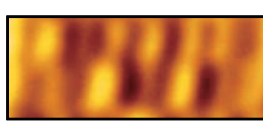

MFM images

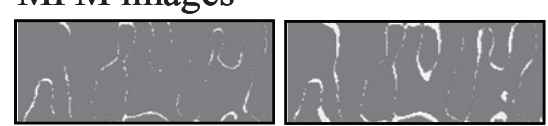

Difference images
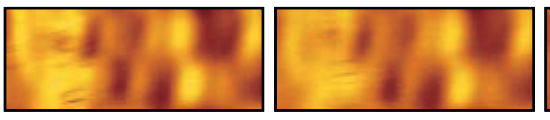

MFM images

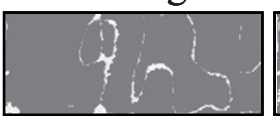

Difference images

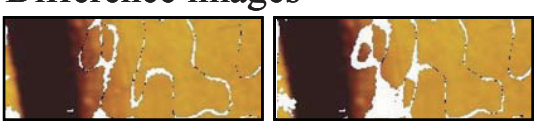

AFM image + Difference images

(c)
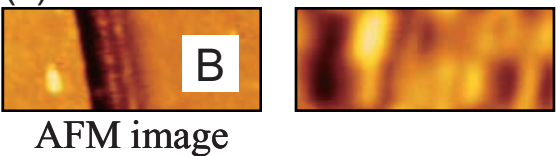

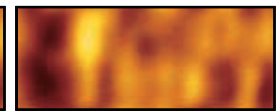

MFM images

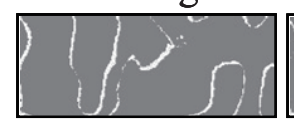

Difference images

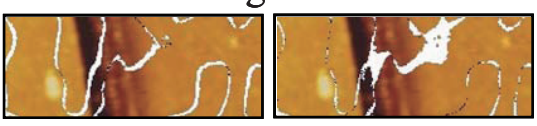

AFM image + Difference images
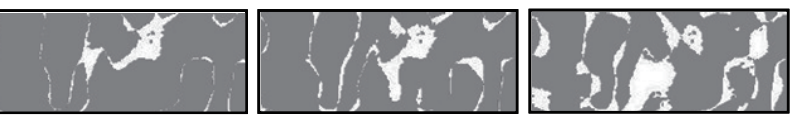

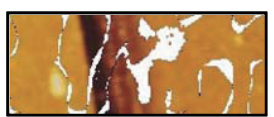

3

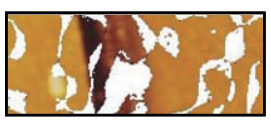

$3 \overline{00 \mathrm{~nm}}$

2

Magnetic field (kOe)

4

Fig. 6 MFM images variation is after applying magnetic filed (first row) and difference images (second row). White contrast in the difference images shows the regions where the local magnetization structure has changed on applying perpendicular magnetic field when compared with the initial magnetization structure (0 kOe). (a) AFM image, MFM images, and difference images of an area with no mechanical scratches. (b), and (c) correspond to similar data taken around the mechanical scratches of A and B.

度 2 kOe（Fig. 4(d)）まで磁化状態の変化は殆ど認められないが, $3 \mathrm{kOe}$ の磁場印加処理後の MFM 像 (Fig. 4(e)) では, 明コントラ ストから暗コントラストに変化し始めている. 5 kOe (Fig. 4(g)) および $6 \mathrm{kOe}$ (Fig. 4(h)) の磁場印加により, 直線帯状の暗 MFM コントラストが認められ始めている. MFM 像で観察された直線 帯状の暗コントラストが現れた理由として MFM 測定における磁 気情報と形態情報の重複効果が考えられる. ディスク試料面と探 針間距離を接近させた場合, 試料に部が存在するとこの部分で は探針に働く原子間力が減少する. 磁化強度変化量が全体的に低 下した磁気情報にこの様なスクラッチの形状情報がオーバーラッ プしたため, 暗コントラスト領域として観察されていたものと解 釈される.

次に，スクラッチ形成領域において深さが記録磁性膜に達して
いない 領域 (スクラッチ左端から 197〜369 nm の範囲) について 検討する.この領域は, 印加磁場強度が $1 \mathrm{kOe}$ 程度 (Fig. 4(c)) ま では，スクラッチ周辺の記録ビットの磁化状態に変化は殆ど認め られないが， $2 \mathrm{kOe}$ の磁場印加処理（Fig. 4(d)）を行うことによ り, E で示したスクラッチの左端から約 $270 \mathrm{~nm}$ 離れた領域にお いて暗コントラストビットが明コントラストビットに変化し， ス クラッチの左端より約 $320 \mathrm{~nm}$ 離れた $\mathrm{F}$ で示した領域においても 磁化状態の変化が認められている. スクラッチが存在しない場合

(Fig. 3), 印加磁場強度 $2 \mathrm{kOe}$ では磁化状態変化が生じないのに 比べ, より低い磁場強度で磁化状態の変化が起こり始めている. この磁場強度は媒体保磁力の $43 \%$ であり, スクラッチ形成された 場合は保磁力の半分以下の外部磁場強度で記録磁化状態の変化が 生じ始めることを示寸ものと解釈される. この記録磁化状態変化 
が生じた理由は，スクラッチの形成により記録磁性膜を構成する 磁性結晶粒が機械的な変形と応力を受けて, この部分の磁気異方 性が低下し，また磁性結晶粒間に働いている磁気的な相互作用の 影響によりスクラッチの深さが記録磁性膜に達していない領域ま で磁化反転が起こり易くなっているためと考えられる.この結果, 保磁力より低い磁場印加条件下でも磁化反転が生じ始めたものと 考えられる. $3 \mathrm{kOe}$ の磁場印加処理後の磁化状態 (Fig. 4(e)) では, 明コントラスト領域がスクラッチの左端から約 $400 \mathrm{~nm}$ 離れた領 域まで拡大しているのが認められる。 また，スクラッチ端から約 $600 \mathrm{~nm}$ 離れた G に示す領域でも暗コントラストビットの端部か ら僅かながら明コントラスト面積が拡大寸る傾向が認められるが, この変化はスクラッチが存在しない場合 (Fig. 3) とほぼ同様であ る. この様な観察結果より, スクラッチ $\mathrm{A}$ の近傍では垂直磁場を 印加した場合, 磁化反転がスクラッチの影響を受けて起こり易く なる傾向はスクラッチの深さが記録磁性膜に達していない領域ま で及んでいることが明らかになった。

\section{3 浅いスクラッチの影響（最大深さ $7 \mathrm{~nm}$, 幅 $222 \mathrm{~nm}$ ）}

Fig. 5 に, ディスク試料に浅いスクラッチを形成した場合の磁化 状態の観察結果を示寸. Fig. 5(a)はAFM 像, Fig. 5(b) (h)はMFM 像で，(b)は磁場無印加状態，(c)〜(h)は1〜6 kOe の外部磁場をそ れぞれステップ状に印加後に観察した同一箇所の MFM 像である. このスクラッチはFig. 2(b)の断面プロファイル B に対応してお り, 最大深さは $7 \mathrm{~nm}$ である. スクラッチ部および近傍の MFM 像から明らかなように, 磁場無印加状態 (Fig. 5(b)) では, スクラ ッチの直下と周辺部の記録ビット形状の変化は認められず, スク ラッチが記録磁化状態に影響を殆ど与えていないことが分かる. 先に観察した最大深さが $13 \mathrm{~nm}$ のスクラッチAの場合, スクラッ チ直下の記録磁化情報が変形していたのに対し, 最大深さが $7 \mathrm{~nm}$ のスクラッチ B では記録磁化情報の変形は殆じ生じていない. デ イスク試料の保護膜厚 $(5 \mathrm{~nm})$ と記録磁生膜厚 $(28 \mathrm{~nm})$ を考慮 すると, スクラッチの最大深さが記録磁性膜厚の約 $30 \%$ にぶ場 合（スクラッチ A）では記録磁化情報が失われているのに対し， 約 $7 \%$ 程度と少ない場合（スクラッチB）では磁場を印加しない 状態では磁化状態に殁ど変化が起こっていないことになる.この 試料に磁場印加を行った場合, $1 \mathrm{kOe}$ 程度までは, 記録ビットの 磁化状態に変化は殆ど認められないが，2 kOe の磁場印加処理を 行うことにより (Fig. 5(d)), H 部で示すスクラッチが保護膜厚を 超えて記録磁性層にまで及んでいる領域（スクラッチ左端から 65 $\mathrm{nm}$ までの範囲) で暗コントラストビットが縮小して明コントラス トに変化しているのが認められる. また, I 部で示したスクラッチ の深さが記録磁性膜に達していない領域（スクラッチ左端から 65 〜222 nm の範囲) においてスクラッチの左端から約 $140 \mathrm{~nm}$ 離れ た領域においても磁化状態の変化が起こり始めている. スクラッ チ深さが記録磁性層膜厚の $7 \%$ 程度と浅い場合でも外部磁場の影 響を受けて, 磁化状態変化が起こり易くなっていることが分かる. 更に, J部に示寸ようにスクラッチ端部から約 $90 \mathrm{~nm}$ 離れた領域 においても磁化状態の変化が認められている. $2 \mathrm{kOe} の$ 外部磁場 印加した場合，スクラッチA では (Fig. 4(d)), スクラッチの左端 から約 $320 \mathrm{~nm}$ 離れた領域まで磁化状態变化が生じているのが認
められたのに比べ, より狭いスクラッチ B の場合はスクラッチ左 端から約 $140 \mathrm{~nm}$ 離れた領域までの範囲で磁化状態変化が起こり 易くなっているのが分かる. 磁化状態変化の起こり易さに及ぼす スクラッチの影響は深さだけではなくその幅も関係していると考 えられる. これら二要因が磁化状態変化に及ぼす効果の違いを調 ベるためには, 例えばスクラッチ深さを一定として幅を変えた試 料を用いた実験を行う必要がある. 今後の研究課題であると考え られる. $3 \mathrm{kOe} の$ 外部磁場印加処理により, スクラッチ直下およ び端部においても大きな磁化状態変化が生じ始めていることが分 かる (Fig. 5(e)). また, K 部に示すようにスクラッチ端部から約 $360 \mathrm{~nm}$ 離れた領域て磁化状態変化が認められているが, これはス クラッチが存在しない場合の傾向（Fig. 3）とほぼ同様であり，ス クラッチ端部から $300 \mathrm{~nm}$ 以上離れた領域ではスクラッチによる 影響は殆ど及んでいないものと思われる. 一方, $4 \mathrm{kOe}$ 磁場印加 後 (Fig. 5(f)) では, 例えばL部に示すようにスクラッチ直下およ び端部で暗コントラスト領域の拡大が認められる.この現象はス クラッチ A で観察されたのと同様に, MFM 測定におけるディス ク試料と探針間に働く原子間力の影響が主な原因であると考えら れる.

以上の結果より，スクラッチがディスク試料に形成されると， そのスクラッチの直下および周辺部で磁化状態変化が起こり易く, しかもその変化はスクラッチの深さだけではなく幅も影響を与え ているものと解釈される.

\section{4 MFM 画像処理による磁化反転領域の抽出}

磁場印加処理によって記録磁化状態に変化が生じた領域の二次 元分布を抽出するため, 初期状態 (磁場印加処理前) と磁場印加 処理後に観察した MFM 画像の差分二值化を試みた. Fig. 6(a)に スクラッチが存在しない場合の MFM 像（上段）およひ磁場印加 処理後と初期状態の差分二值化像（下段）を示寸.ここでは媒体 保磁力 $(4.7 \mathrm{kOe})$ 未満の $4 \mathrm{kOe}$ までの磁場印加処理を行った場合 の変化を示している. 差分二值化では, 初期状態 (磁場印加処理 前）と各磁場印加処理後の MFM 像の間で画像差を取り, 変化が 生じた箇所を白コントラストとして抽出している. 二值化差分像

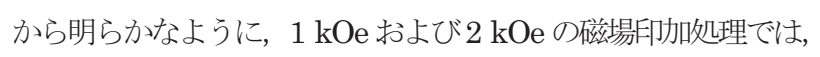
明コントラストビットと暗コントラストビットの境界に相当する 磁化遷移領域で初期状態から僅かながら磁化状態が変化している のが観察されている. 磁場印加強度が増大するにつれて, トラッ ク境界部領域において磁化状態変化が優先的に生ずる傾向が認め られる. MFM 像間の比較だけでは磁化状態変化が生じているか 判断しにくい場合でも, 差分像を得ることによって磁化状態の小 さい変化まで明瞭に観察できることが分かる.

Fig. 6(b), (c)にディスク試料表面にスクラッチを形成した場合の 磁場印加処理後の MFM 像 (上段), 磁場印加処理後と初期状態の 差分二值化像（中段）および AFM 像に差分二值化像を重ね合わ せた像（下段）をそれぞれ示す。これらの観察箇所は Fig. 2(b)の 断面プロファイル中の A 部およびB 部に対応している. Fig. 6(a), (b)の AFM 像に差分二值化像を重ね合わせた像（下段）の $2 \mathrm{kOe}$ 外部磁場印加処理において, 前項で説明した通り, スクラッチの 直下およひ端部領域から変化が顕著に起こっていることが認めら 
れる.

次に, 記録磁化状態変化量を面積比として定量解析を行うため, 得られた差分二值化像の変化率を求めた. 1 画像を $212 \times 83$ ピク セルの中で白コントラストのピクセル数が占める割合を求めるこ とにより磁化状態が変化した領域の面積比を算出した. 画像ドリ フトの補正による画像の変形は 1 ピクセル以内に抑えることがで きるため，この処理に伴う変化率の最大誤差は $4 \%$ になる. Fig. 6(a)に示した試料表面にスクラッチが存在しない場合の変化率は, $1 \mathrm{kOe}, 2 \mathrm{kOe}, 3 \mathrm{kOe}$ および $4 \mathrm{kOe}$ 外部磁場印加の場合, それぞ れ $5.6 \%, 9.1 \%, 13.5 \%, 19.9 \%$ となった. $1 \mathrm{kOe} \sim 2 \mathrm{kOe}$ 外部 磁場印加では変化率は大きくないが, 外部磁場印加強度を $3 \mathrm{kOe}$, $4 \mathrm{kOe}$ と増加させることにより記録ビット境界およびトラック境 界付近で優先的に変化が起こり, 変化率が増大寸ることが分かる. ここで, $1 \mathrm{kOe}$ および $2 \mathrm{kOe}$ の外部磁場印加を行った場合の変化 率が最大誤差の 4 \%を上回っているが，この原因として二值化処 理において中間色領域の判別誤差が含まれていることが考えられ る. Fig. 6(b)および(c)に試料表面にスクラッチを形成した場合の変 化率を求めた結果を示寸. スクラッチの最大深さが $13 \mathrm{~nm}$ の場合

(Fig. 6(b)) の磁化状態変化率として, $1 \mathrm{kOe}, 2 \mathrm{kOe}, 3 \mathrm{kOe}$ お よび $4 \mathrm{kOe}$ 外部磁場印加により,それぞれ $6.3 \%, 12.6 \%, 23.4 \%$, $43.2 \%$ の值が得られた. また, スクラッチの最大深さが $7 \mathrm{~nm}$ の 場合 (Fig. 6(c)) の磁化状態変化率として, $1 \mathrm{kOe}, 2 \mathrm{kOe}, 3 \mathrm{kOe}$ および $4 \mathrm{kOe}$ 外部磁場印加により，それぞれ $8.1 \%, 10.2 \%, 14.3 \%$, $25.3 \%$ 值が得られた. スクラッチが存在しない場合の変化率と 比較すると, スクラッチが存在する場合は $2 \mathrm{kOe} の$ 外部磁場印加 を寸ることにより変化率変動が顕著に増大していることが明らか となった．また，スクラッチ幅が広い場合，幅が狭いスクラッチ に比べて変化率の増加が大きいことが明らかである.

次に, 異なるスクラッチ幅が及ぼす磁化状態変化の定量解析を 行うため, 得られた AFM 像に差分二值化像を重㸚合わせた像か ら磁化状態変化が生じた領域を抽出した. このときの計測方法は, スクラッチの深さが記録磁生膜に達していない領域において磁化 状態変化が生じた場所を 10 箇所プロットして, スクラッチ左端か らその距離の平均值を算出した．スクラッチの最大深さが $13 \mathrm{~nm}$ の場合 (Fig. 6(b)) の磁化状態変化が生じた領域の平均值として, $1 \mathrm{kOe}, 2 \mathrm{kOe}, 3 \mathrm{kOe}$ および $4 \mathrm{kOe}$ 外部磁場印加により, それぞ れ $310 \mathrm{~nm}, 330 \mathrm{~nm}, 380 \mathrm{~nm}, 400 \mathrm{~nm}$ の值が得られた. スクラ ッチの深さが記録磁性膜に達していない領域（スクラッチ左端か ら 197〜369 nm の範囲) を考慮すると, $2 \mathrm{kOe}$ 以下の磁場印加処 理ではこの領域の磁化状態変化が優先的に生じていることが分か る. また, スクラッチの最大深さが $7 \mathrm{~nm}$ の場合 (Fig. 6(c)), $1 \mathrm{kOe}$, $2 \mathrm{kOe}, 3 \mathrm{kOe}$ および $4 \mathrm{kOe}$ 外部磁場印加により, それぞれ $105 \mathrm{~nm}$, $135 \mathrm{~nm}, 225 \mathrm{~nm}, 250 \mathrm{~nm}$ の值が得られた. スクラッチの深さが 記録磁性膜に達していない領域はスクラッチの左端から 65〜222 $\mathrm{nm}$ であるため, $3 \mathrm{kOe}$ の外部磁場印加処理までこの領域内の変化 が著しいことが分かる．また，スクラッチ幅が広い場合，幅が狭
いスクラッチに比べて磁化状態変化が生じる範囲も広いことが分 かった. 以上より, スクラッチの深さが記録磁生膜に達していな い領域では, 保磁力よりも遥か炕低い外部磁場によって磁化状態 変化が起こり易いことが確認された。

\section{4. まとめ}

本研究では，垂直磁気記録方式のハードディスク表面にスクラ ッチが存在した場合，記録磁化状態に及ぼす外部磁場の影響を明 らかにすることを目的に，磁気力顕微鏡を用いて磁化状態観察を 行った. ディスク試料表面にスクラッチが存在しない場合, 媒体 保磁力より $30 \%$ 程度低い外部磁場印加処理により, 主としてビッ 卜端部付近から磁化状態が変化し始める様子が観察された. 一方, ディスク試料表面にスクラッチが存在すると，保磁力の半分以下 の外部磁場印加処理を行うことにより, 磁化状態変化がスクラッ チの直下および周辺部より優先的に変化することが分かった．ま た, スクラッチの幅が広い程, 外部磁場印加をしたときの磁化状 態の変化が大きいことが認められた. MFM 像の二值化差分像を 取り磁化状態変化の変化率を求めることにより, 磁化状態変化の 定量解析が可能であることを示した。

謝辞 観察試料の磁気特性測定では(株)日立製作所中央研究所の 平山義幸主任研究員のご協力を頂きました. また, 本研究の一部 はNEDO の援助を受けて行いました. ここに謝意を表します。

\section{References}

1) M. Igarashi, M Hara, Y Suzuki, A Nakamura, and Y Sugita: IEEE Trans. Magn., 39, 2303 (2003).

2) J. W. Wang, M. Z. M. Yuan B. Liu, and J. Ding: IEEE Trans. Magn., 36, 2686 (2000).

3) B. Valcu, R. Brockie, Y. Nan-Hsiung, and H. J. Richter: IEEE Trans. Magn., 43, 2115 (2007).

4) E. N. Abarra, H. Sato, M. Suzuki, and I. Okamoto: IEEE Trans. Magn., 36, 2450 (2000).

5) Y. Yasui, K. Shimomai, and M. Futamoto: J. Magn. Soc. Jpn., 31, 312 (2007).

6) H. Takahoshi, H. Saito, S. Ishio, T. Yamaoka, and I. Okamoto: J. Magn. Soc. Jpn., 26, 284 (2002).

7) T. Yoshimura, S. Oshika, and M. Futamoto: J. Magn. Soc. Jpn., 33, 199 (2009).

8) T. Liew, W. W. Siong, K. C. Shiau, and T. L. Chwee: Tribol. Int., 33, 611 (2000).

9) M. Suk, and D. Jen: IEEE Trans. Magn., 34, 1711 (1998).

10) J. Xu, M. Furukawa, A. Nakamura, and M.Honda: IEEE Trans. Magn., 45, 893 (2009).

11) K. Nagano, S. Sasaki, and M. Futamoto: J. Phys. Conf. Ser., 200, 102006 (2010).

12) W. Pei, H. Saito, and S. Ishio: IEICE. Tech. Rep., 30, 11 (2006)

2009年10月20日受理，2010年2月1日再受理，2010年3月17日採録 